\title{
The war puzzle: contradictory effects of international conflicts on stock markets
}

\author{
Brune, Amelie ; Hens, Thorsten ; Rieger, Marc Oliver ; Wang, Mei
}

\begin{abstract}
We study stock market reactions to large international military conflicts since World War II. Using a news analysis proxy for the estimated likelihood that a conflict will result in a war, we find that an increase in the war likelihood tends to decrease stock prices, but the ultimate outbreak of a war increases them. In cases when a war starts surprisingly, however, the outbreak of a war decreases stock prices. We show that this puzzle cannot be explained by risk or ambiguity aversion or by expectations about a quick end of the war.
\end{abstract}

DOI: https://doi.org/10.1007/s12232-014-0215-7

Posted at the Zurich Open Repository and Archive, University of Zurich

ZORA URL: https://doi.org/10.5167/uzh-119581

Journal Article

Accepted Version

Originally published at:

Brune, Amelie; Hens, Thorsten; Rieger, Marc Oliver; Wang, Mei (2015). The war puzzle: contradictory effects of international conflicts on stock markets. International Review of Economics, 62(1):1-21.

DOI: https://doi.org/10.1007/s12232-014-0215-7 


\title{
The war puzzle: contradictory effects of in- ternational conflicts on stock markets
}

\author{
Amelie Brune* \\ Thorsten Hens ${ }^{\dagger}$ \\ Marc Oliver Rieger ${ }^{\ddagger}$ \\ Mei Wang ${ }^{\S}$
}

May 6, 2014

\begin{abstract}
We study stock market reactions to large international military conflicts since World War II. Using a news analysis proxy for the estimated likelihood that a conflict will result in a war, we find that an increase in the war likelihood tends to decrease stock prices, but the ultimate outbreak of a war increases them. In cases when a war starts surprisingly, however, the outbreak of a war decreases stock prices. We show that this puzzle cannot be explained by risk or ambiguity aversion or by expectations about a quick end of the war.
\end{abstract}

JEL classification: G11, G14, G19.

Keywords: International conflicts, war, stock market reaction, news analysis, behavioral finance.

\footnotetext{
${ }^{* *}$ Ph.D. student at the Department of Banking and Finance, University of Zurich Plattenstrasse 32, 8032 Zurich, Switzerland. amelie.brune@bf.uzh.ch

${ }^{+}$Swiss Finance Institute professor at the Department of Banking and Finance, University of Zurich, Plattenstrasse 32,8032 Zurich, Switzerland and NHH Bergen, Norway. thorsten.hens@bf.uzh.ch

${ }^{\ddagger}$ Professor of Banking and Finance at the University of Trier, 54286 Trier, Germany. mrieger@uni-trier.de

${ }^{\S}$ Professor of Behavioral Finance at the WHU Otto Beisheim School of Management, Germany. mei.wang@whu.edu
} 


\section{Introduction}

"Buy on the sound of the cannon, sell on the sound of the trumpet." is an old proverb from the Napoleonic wars, attributed to London financier Nathan Rothschild. It suggests that the start of a war is a good time to buy stocks, and that they should be sold once the war is over. The rationale behind this advice is that investors tend to overreact to the bad news of a coming war, leading to underpricing, and that they overreact to the good news of the end of a war in a similar way, leading to overpricing.

Economists have been concerned with the causes and consequences of international military crises for more than one hundred years, one of the first contributions being the work of Keynes (1919). Further work focused on the interplay between economy and war (Holsti and North (1966), Russett and Hanson (1975), and Collier and Hoeffler (1998)), as well as on the impact of war on financial markets throughout history (Frey and Kucher (2000)).

Recently, the financial market reaction induced by international conflicts has received substantial interest in finance. News analysis has been used to reflect the perceived risks and consequences of wars. In an early pioneering study using content analysis of news, Holsti and North (1966) demonstrate that security prices are related to rising international tensions during the outbreak of World War I. In a more general framework, Niederhoffer (1971) codes the headlines on world events on a seven-point good-bad scale in order to examine the impacts of news, and Cutler, Poterba, and Summers (1989) analyze the stock market reaction to world news (including wars) from 1926 to 1985 . To quantify the effect of international conflicts on stock prices, Goldstein (1992) constructed a scale to code conflictive versus cooperative events that can be used to assess the impact of war risk, as it was pointed out by Schneider and Troeger (2006). There are further studies on the relation between world news and financial markets, in particular during times of crises:

Elmendorf, Hirschfeld, and Weil (1996) study British bond market reactions to news by comparing weeks with important news to those without such news. Similarly, Rigobon, and Sack (2005) distinguish the days with war-related news to those without these news to measure the impact of war risk on financial markets.

Whereas all of these studies either consider particular conflicts or the impact of war risk on financial markets during (at first glance) peaceful times, in this paper we want to focus on a slightly different aspect, namely wars with a "prologue", i.e., wars which follow a period of tension. In this type of war we distinguish two phases: in the first phase, where cannons are still silent, there is an increasing danger of a war, possibly interrupted by times of hope for a peaceful resolution. Afterwards, in the second phase, the "sound of the cannon" starts and war breaks out.

The surprising finding of our analysis is that often the reaction of the stock market to the likelihood of a war is different between these two phases: whereas in the pre-war phase an increased likelihood of war decreases market prices, the outbreak of the war itself, so to speak the increase of the likelihood from $99 \%$ to $10 \%$, increases market prices. On the day of the outbreak of some specific war, news coverage is clearly focused on this particular event. The development of the stock market index then reflects the market's reaction to and evaluation of the event, which is thus far from random. 
We observe this striking puzzle for a number of larger wars, including the Iraq War and World War II. In all cases we study the impact on the US stock market as measured by the S\&P 500 or Dow Jones Industrial Average. To complement our results, we also analyze all other international crises with large impact since World War II, in particular wars that started unexpectedly, such as the Korean War.

This paper is organized as follows. Section 2 discusses different proxies to estimate the likelihood of war. Section 3 analyzes the Iraq War in 2003 using different likelihood measurements and shows that a puzzle in the development of stock prices along the evolvement of this international crisis can be observed. Using further examples of international wars in Section 4, we show that this phenomenon does not seem to be restricted to the war in Iraq. Section 5 discusses possible explanations for the puzzle and rejects some - at first glance natural - explanations. Section 6 concludes.

\section{Estimating the likelihood of war}

To analyze market reactions to changes in war likelihood, we first need to find appropriate proxies for this likelihood. To this end, we analyze the Iraq War as several independent estimates for the probability of war are available here. This war then serves as a benchmark to establish a simple yet robust proxy using news that we can then readily apply to earlier wars where other data are not available.

The Iraq crisis started to become serious on January 28, 2003 when President George W. Bush announced a possible attack on Iraq even in the absence of a UN resolution legitimating this course of action. After the ultimatum proposed to Saddam Hussein on March 17 to leave Iraq within 48 hours had expired, the first military intervention by the US started immediately in the early morning of March 20. Later that morning, President George Bush formally announced the Operation Iraqi Freedom.

Following Wolfers and Zitzewitz (2009), we use two independent estimates for the probability that a war would take place in Iraq: the first is the so-called "Saddameter", an expert estimate for the likelihood of an invasion of Iraq which was published on a daily basis by William Saletan on http://www.slate.com. This estimate provides us with data from November 2002 to March 18, 2003. The second is the so-called "Saddam Security", a security that existed on the online exchange www.tradesports.com and which was designed to pay a certain amount if and only if Saddam Hussein, president of Iraq, were still in power at a certain date. As a war was expected to end his rule over Iraq, Saddam Security prices gave a good probability estimate for the likelihood of war before the designated date (see Amihud and Wohl (2004)). This security was available with different maturity dates, where only March 2003 and June 2003 securities had a long enough price series. We use the June security, as the pattern of the March security is somehow obfuscated by the fact that even though the probability for a coming war increased, it was at times not at all clear whether the eventual war was over before the end of March.

As another proxy we studied news data from the New York Times. We counted how many articles with the key words "war" and "Iraq" appeared in each day's issue. To show that this variable is closely related to the above mentioned probability measurements and that it provides the same qualitative indications about the war likelihood, we regress each of the two measurements (i.e., the Sad- 
dameter and the Saddam Security) on our news proxy. The results are reported in Table 1. We see that the news variable is positively correlated with the Saddameter, that is, the expert measurement on the war likelihood and the number of (mostly negative) news items run in the same direction. The comovement between the Saddameter and the news variable between November 2002 and March 2003 is depicted in Figure 1(a) and is negatively related to the development of the S\&P 500. Similarly, the news proxy is positively related to the Saddam Security.

$<$ Table 1 about here>

$<$ Figure 1 about here>

\section{The Iraq war puzzle}

As mentioned earlier, a puzzle can be observed when analyzing data of stock market prices prior to and at the onset of a war. The relation between stock market prices and the probability of an international conflict developing into a war is negative as long as the conflict is still evolving. However, it becomes positive at the actual onset of the war, thus a positive shock in the stock market can be observed when the war likelihood increases to $100 \%$. In other words, an increasing war likelihood seems to decrease stock prices, while the outbreak of the war itself seems to increase them. This is what we call the "war puzzle".

To provide empirical evidence for this puzzle, we begin with an analysis of the Iraq War in 2003. The main reason for this approach is the fact that for this war we are able to use two alternative measurements of the probability of war, namely the Saddameter and the news variable described in Section 2 . As previously explained, this has the advantage that we are able to conduct econometric analyses for both types of probability measures in the same war. Hence, showing that the news variable is a valid proxy for war likelihood, we can then use this variable to analyze periods of war where no alternative probability measures are available.

$<$ Table 2 about here $>$

$<$ Table 3 about here $>$

Analyzing the characteristics of the S\&P 500, news, and the Saddameter, we find that these timeseries are non-stationary in levels, but stationary in first differences (see Table 2 for augmented Dickey-Fuller test statistics for unit roots). Moreover, we find evidence for a cointegrating relationship between the S\&P 500 and each probability measure of order one (see Table 3 ). This leads us to the choice of an error correction model to appropriately model the relation between the US stock market and war likelihood. The econometric models employed to study the stock market in the pre-war phase are

$$
\begin{gathered}
\Delta S P 500_{t-1}=\beta_{1} \Delta S P 500_{t-2}+\beta_{2} \Delta \text { news }_{t}+\gamma\left[S P 500_{t-2}-\propto_{0}-\propto_{1} n e w s_{t-1}\right]+\varepsilon_{t} \\
\Delta S P 500_{t-1}=\beta_{1} \Delta S P 500_{t-2}+\beta_{2} \Delta S a d d_{t-1}+\gamma\left[S P 500_{t-2}-\propto_{0}-\propto_{1} S a d d_{t-1}\right]+\varepsilon_{t}
\end{gathered}
$$

where $\triangle S P 500$ measures absolute daily changes in the S\&P 500 and the error correction parameter $\gamma$ captures the degree to which deviations from an equilibrium in the previous period (captured by the error term) affect current values. Hence, $\gamma$ is expected to be negative if a long run equilibrium 
relationship prevails. Note that the functional form of most models used in this and the following sections is such that the explanatory variable is lagged forward relative to the dependent variable. While this may seem slightly counterintuitive at first sight, the reason is that there is a certain delay between the stock market pricing an event and its actual publication in the newspaper. ${ }^{1}$

The estimated coefficients are presented in columns 1 and 2 of Table 4 . Both news and the Saddameter are highly significant at the $1 \%$ and $5 \%$ level, respectively, and indeed indicate a negative relationship between stock prices and war likelihood. An increase in the probability of war is thus associated with decreasing stock market prices. ${ }^{2}$ In particular, an increase in the difference of the number of news items, $\Delta n e w s_{t}$, by one unit leads to a decrease in the difference in the S\&P $500, S P 500_{t-1}$, by 0.507 points. Similarly, an increase in the difference of the Saddameter value, $\Delta S a d d_{t-1}$, by one percentage point leads to a decrease in the difference in the S\&P $500, \Delta S P 500_{t-1}$, by 1.112 points. The one day lag in the news variable can be attributed to the time required for physical publication of the newspaper. Since both probability measures yield the same implications, they may both be regarded as valid proxies, which ensures that we can employ the news variable as a valid proxy also in periods where alternative probability measures are not available.

$<$ Table 4 about here>

To study the behavior of the stock market at the onset of the war, we conduct an analysis for structural breaks in the development of the stock market index. To this end, cumulative returns of the S\&P 500 are regressed on a binary dummy $D_{t}$ defined as

$$
D_{t}=\left\{\begin{array}{l}
0 \text { if } t<\tilde{t} \\
1 \text { if } t \geq \tilde{t}
\end{array}\right.
$$

where $\tilde{t}$ indicates a potential structural break, and a time window of size $51^{3}$ around $\tilde{t}$ is used to obtain a set of models of type

$$
S P 500_{t}=\beta_{0}+\beta_{1} D_{t}+\varepsilon_{t} .
$$

That is, $\tilde{t}$ is varied over time until the largest associated $R^{2}$ is found, where we suppose that the actual onset of a war, and hence the observed structural break denoted by $t_{0}$, lies in close proximity. ${ }^{4}$ Note that while we are aware of potential problems of non-stationarity in the cumulative returns, our analysis of structural breaks would not be feasible using first differences here. Our interest lies in potential increases in stock market values at the beginning of a war, which has to be separated from the question of average increases or changing trends. The problem thus is to weight an interesting question with the obvious problems of not using differences in the model in order to resolve the issue.

The results are illustrated in Figure 1 (b). The largest $R^{2}$ obtained amounts to 0.7665 and is associated with March 18, 2003 while on March 20, 2003, the invasion of Iraq took place $\left(R^{2}=0.6898\right)$. Hence, the true structural break can be relatively well predicted. ${ }^{5}$ The S\&P 500 increases by 46.4 points at the time of the predicted structural break and by 47.8 points at the time of the invasion two days later. Although it may prove difficult to interpret this absolute change in the stock market index at the onset of the war and compare it across conflicts, we refrain from calculating relative changes, for instance. As the volume of news items clearly differs over time, a comparison of relative values over time would be meaningless and thus reveal no further insights for the analysis. 


\section{The war puzzle - a general phenomenon}

The results of the previous section could either be a general phenomenon or just an idiosyncrasy of the Iraq War. In this section we therefore extend the analysis to other wars with large international impact since World War II. We face two problems here: first, we need to decide which wars to include, and second, the number of large scale wars during this time was - fortunately - not big enough to use a single econometric approach for all wars. Instead of performing a unified analysis, we are forced to study the conflicts separately. As any event study involving data on stock market indices during international military conflicts, our subsequent analysis is necessarily based on a small number of observations.

We solve the above-mentioned selection problem by using the list of the most costly wars to the US (and thus arguably to the US economy) as composed by Stephen Daggett ${ }^{6}$ (see Table 5). In the following we will study each of the wars from this list, where we distinguish between wars with a surprising start and wars with a longer prelude. Since the wars took place at very different times, with news traveling at different speeds, the econometric models we apply necessarily differ in details.

$<$ Table 5 about here>

\subsection{World War II (1939-45)}

To analyze World War II, two starting dates can be studied: on the one hand, the German invasion of Poland on September 1, 1939, and on the other, the Japanese attack of Pearl Harbor on December 7, 1941, dragging the US into the war.

We first study the former event as it had a large prelude while we will study the latter rather surprising one in Section 4.6. To analyze it in an econometric setting, a first differences approach of the form

$$
\Delta D J I_{t-1}=\beta_{0}+\beta_{1} \Delta D J I_{t-2}+\beta_{2} \Delta \text { news }_{t+1}+\beta_{3} \Delta n e w s_{t}+\beta_{4} \Delta n e w s_{t-1}+\varepsilon_{t}
$$

is most appropriate. The stock market is described by absolute daily changes in the Dow Jones Index, $\Delta D J I$, and the war likelihood is from now on captured by the news proxy as established in Section 2, i.e. in this case the number of articles in the New York Times featuring the key words "war" and "Poland". Figure 2(a) depicts the relation between the Dow Jones Index and the probability of war between June and September 1939. Column 3 of Table 4 shows the regression results obtained from estimating this equation. The marginal effect of the news variable is significantly negative for all different lags $\Delta n e w s_{t-1}, \Delta n e w s_{t}$, and $\Delta n e w s_{t+1}$ ranges from $-0.195\left(\Delta n e w s_{t-1}\right)$ to $-0.284\left(\Delta n e w s_{t}\right)$ points. Figure 2 (b) illustrates the results obtained from the structural break analysis of type

$$
D J I_{t}=\beta_{0}+\beta_{1} D_{t}+\varepsilon_{t} .
$$

September 5, 1939 is identified as the most likely structural break in the data set $\left(R^{2}=0.8274\right)$. In fact, this lies close to the German attack of Poland being the critical event on September 1, 1939 $\left(R^{2}=0.7244\right)$. The time lag may be explained by the slower speed of news publication at that time. 


\subsection{Vietnam War (1955-75)}

The Vietnam War distinguishes itself from other wars by the fact that its time line is less clear, but the onset of the large scale US involvement is set in 1965. The development of the Dow Jones Index and the news variable between February 1964 and March 1965 is depicted in Figure 3(a).

<Figure 3 about here>

The most suitable model for this war is a time-series approach of type

$$
\Delta D J I_{t-1}=\beta_{0}+\beta_{1} \Delta D J I_{t-2}+\beta_{2} \Delta n e w s_{t}+\beta_{3} \Delta n e w s_{t-1}+\varepsilon_{t} .
$$

The regression results for this model are presented in column 4 of Table 4. Again, we see a significant negative relation between the war likelihood and the development of stock prices. Figure 3(b) illustrates the results for the analysis of structural breaks. We see that the ad hoc regression identifies April 15, 1965 as the event associated with the largest coefficient of determination, $R^{2}=0.7860$. In fact, one critical event coincides with this date: it marks the first US and South Vietnamese bombing of Viet Cong positions. The jump in cumulative returns is significantly positive at the $1 \%$ level and amounts to an increase in the Dow Jones Index by 28.01 points.

Note that, for the war in Vietnam, the analysis does not exactly describe the pre-war period and the distinct outbreak of the war itself, but nevertheless proves to be a useful method to analyze the reaction of cumulative stock returns to war news within a prolonged period of tensions.

\subsection{Gulf War (1990-91)}

The Gulf War ${ }^{7}$ started with the invasion of Kuwait by Iraq on August 2, 1990 and ended with the defeat of Iraq by the US and their allies on February 28, 1991. The relevant date for our analysis is January 17, 1991 when the Operation Desert Storm (with the goal of liberating Kuwait) was started by massive aerial bombing. The Gulf War moved into its second and much larger phase then. As such, our news series covers the time span up to this date, which can be interpreted as a pre-war phase from the perspective of the US and their allies.

Analyzing this relation with a time-series approach, column 5 of Table 4 shows the results. We see once more that there is empirical evidence for a significant negative relation between news and stock market prices. The analysis for structural breaks in the development of cumulative returns (see Figure 4) identifies February 4, 1991 as the break point $\left(R^{2}=0.8457\right)$ which, however, lies some days after the initial aerial bombing. In fact, the closest real event to this indication is the Battle of Khafji being the first major ground battle in the Gulf War on January 29, 1991.

<Figure 4 about here>

\subsection{Afghanistan (2001)}


In contrast to the conflicts analyzed in the previous sections, the Afghanistan war, starting in October 2001, had too short a prelude (beginning only after Afghanistan's involvement in the attack on September 11, 2001 became clear) to be analyzed in an econometric setting. However, we can still perform an analysis for structural breaks and show that there exists an increase in stock market prices at the onset of the war. Figure 5(a) depicts the development of the S\&P 500 and news between September and October 2001. Figure 5(b) shows the empirical results from the analysis for structural breaks. Again, an increase in the S\&P 500 around the time of the start of the war can be identified.

$<$ Figure 5 about here>

\subsection{Behavior of other large stock market indices}

Do stock markets in other countries behave similarly to the US market? For the two recent wars with a sufficiently long prelude, i.e. the Gulf War and the Iraq War, Figure 6 shows that Japanese, German, and European stock indices mirror the development of the S\&P 500 quite well. The analysis for structural breaks (see Table 6) shows particularly for the Gulf War simultaneous up-moves at the onsets of war. ${ }^{8}$ The fact that the US, Europe and Japan are strongly interconnected in economic terms may further account for the clear comovement of Nikkei, DAX, and Eurostoxx which can be observed during these two wars in the Middle East. A similar, though less pronounced, comovement also exists for the Afghanistan War. ${ }^{9}$

<Figure 6 about here>

$<$ Table 6 about here>

\subsection{Wars "out of the blue"}

So far we have analyzed wars that had a more or less pronounced prelude. However, there are also some wars with a very fast and unexpected onset. ${ }^{10}$ Most notably, these are:

- the start of the involvement of the United States in World War II (Pearl Harbor) on December 7, 1941,

- the Korean War, which started with the rather unexpected invasion of South Korea by North Korea on June 25, 1950,

- $\quad$ and finally the Gulf War, or more precisely, the invasion of Kuwait by Iraq on August 2, 1990.

Pearl Harbor can indeed be interpreted as a surprising conflict. Although U.S. relations with Japan were deteriorating in 1941, the actual start of the war came as a surprise: a representative survey by Gallup conducted a few days before the attack on Pearl Harbor found that only $52 \%$ of Americans actually expected "that the United States will go to war against Japan some time in the near future" (Canadian Institute of Public Opinion (1941)). What happened was that, not "some time in the near future", but just a few days later, the war started - and not by the US going to war, but by the US being attacked. This is in stark contrast to the situation, e.g., in the Iraq War where the likelihood of a war was already estimated to be above $90 \%$ several weeks before the start of the war (see Figure 1 (a)). 
In all of these cases we cannot expect to find the same pattern which we observed before the outbreak of the wars analyzed in the previous section. There is simply no pre-war phase that could be analyzed and where an increase in the probability of war could decrease stock market prices. ${ }^{11}$

What we can observe, however, is whether the onset of a war led to a sudden increase or decrease in stock market prices. A structural break analysis shows that this is indeed the case for all three wars. However, the pattern is inverted: in all three cases, stock market prices went down significantly at the outbreak of the war. In the case of Pearl Harbor, the Dow Jones Index went down by nearly 3\% in one day, in the case of the Korean War by nearly $5 \%$, and in the case of the Gulf War it went down by around $5.7 \%$ within a week.

\subsection{What's puzzling about the war puzzle}

Our analysis so far has revealed quite a peculiar pattern: on the one hand, stock prices tend to fall when the probability of a war increases and tend to rise when there are signs for a peaceful resolution. However, the actual onset of the war will increase stock market prices.

While this by itself is already puzzling, it becomes even more puzzling considering the evidence that we found about surprising wars (wars without a lengthy prelude): here, we observe that stock market prices tend to decrease once the war breaks out. In other words, whether stock prices decrease or increase when a war breaks out does not seem to depend much on the particular war but more on the previous history or, more precisely, whether the war was surprising or not. But even this observation cannot explain the discrepancy that one and the same war first suggests a pattern that an increase in the likelihood of war decreases stock market prices but then ultimately the onset of the war itself increases them. This cannot easily be accommodated with the idea that stock market prices reflect expectations of the future economic development of a country.

Table 7 summarizes the stock markets' different reactions towards news for all conflicts studied.

$<$ Table 7 about here>

\section{Attempts to explain the puzzle}

\subsection{War as a stimulus package for the US economy}

The first idea about this puzzle might be that it is none: a war can be considered as a stimulus package for the US economy and thus lead to an increase in stock market prices.

However, this line of argument does not work for two reasons: first, Section 4.5 showed that the puzzle also seems to be present for countries which were not involved in the respective war, such as, for instance, Germany in the Iraq War. Second, the explanation fails to explain why before the war, prices fall whenever the war becomes more likely.

Falling prices when war is looming and rising prices when war is starting: only the combination of these two observations makes the war puzzle a puzzle. 


\subsection{Expectations about a quick end of the war}

A natural idea is to consider the time dimension (Schneider and Troeger (2006)): once the war breaks out, it is clear that the trouble will be over soon, thus investors buy stocks again. For example, the Saddam Security can be interpreted as the likelihood of a coming war, but also as expected length of the war (Amihud and Wohl (2004) and Wolfers and Zitzewitz (2009)). Chappell and Eldridge (2000) also suggested psychological explanations such as "despair" and "renewed hope", regarding the UK stock index reactions to the two sub-periods during World War II. There are, however, at least three arguments that lead us to discard this natural looking idea to explain our findings as well:

- Since the Saddam Security works well as a proxy for the estimated probability of war, it is clear that investors did not expect the war to take place in the distant future: recall that the particular security that we studied would only pay out if Saddam Hussein was out of power by June - not long after the war indeed took place!

- While the positive expectation of a quick war that ends the costly and lengthy tensions before might be true, e.g., for the war in Iraq (although with hindsight it turned out to be overly optimistic), this cannot explain the pattern observed at the onset of World War II; given that it was generally not expected that this war would end quickly, given the experience of the four year long World War I.

- The expectation of a quick end to the war cannot explain why investors do not seem to appreciate the increase of the likelihood of a coming war earlier, as this brings the war (and hence its end) closer.

\subsection{Expectations about a devastating outcome of the war}

For the Iraq War, another explanation for the fact that stock prices increased while the war took its course is that, in this case, everybody was afraid of a truly devastating outcome by means of weapons of mass destruction. As it turned out that this did not happen, stock prices eventually increased.

However, this reasoning is neither able to explain why stock prices increased already at the very start of the war - and not a bit later while Saddam Hussein still had time to use weapons of mass destruction if he had them -, nor can it explain why the same pattern is observed in World War II, for instance, where this argument fails to be applicable.

\subsection{The role of the US within each conflict}

There exists a large body of literature on the structure of conflicts from a political perspective. The basic modeling idea is that an aggressor makes an initial surprising move towards his opponent, who then reacts as a defender. Both aggressor and defender can have allies to their aid.

One of the most influential publications within this literature is Schelling (1966). Against the background of the potential use of nuclear weapons during the Cold War, he argues that the purpose of military strategy became intrinsically based on deterrence rather than ultimate victory over the opponent. Deterrence can thus be interpreted as bargaining power to coerce the opponent to behave in a particular way. While the author argues that this power is most successful when it is not actually 
performed, but rather used as a threat, he also notes that, in reality, this bargaining power is often conveyed by some performance of it. War is thus interpreted as a particular type of bargaining process. Other authors argue that war itself is a sign of the previous breakdown of the peaceful bargaining process (see Powell (2002)).

In this paper, we use a data set on US news items and stock prices. An obvious question to ask is thus which role the US played in each of the conflicts analyzed and to what extent this may have an impact on our results.

While there is no obvious relation between a possible aim of deterrence on the part of the US and the development of stock prices, a closer look at the overall position of the US reveals an interesting pattern: the US played an active role in the Vietnam War and the Gulf War (as ally to the defender) and in the Afghanistan War and the Iraq War (as main attacker). In all of these conflicts, stock prices increased at the onset of the war. At first sight, one may argue that it is the active role of the US which influenced the positive development of stock market prices. However, all of these wars did also have a preceding period of increased tension which makes it difficult to disentangle US participation and pre-war phases as possible causes for the direction of stock market developments. This argument can be supported by looking at all unexpected conflicts, namely Pearl Harbor, the invasion of South Korea by North Korea and the invasion of Kuwait by Iraq. The US was the attacked country in the case of Pearl Harbor, and an ally to the defender in the Korean War as well as the Gulf War. In all three cases, the US had not yet assumed an active role within the conflict when stock prices started to decrease. The same problem arises again: we cannot say whether it is the type of role that the US assumed or the character of the crisis that influences the direction of stock price developments. However, there is one exception: when stock prices began to increase at the onset of World War II in September 1939, the US had not yet assumed an active role, either. This can be interpreted as an indication towards the presence of the war puzzle, i.e. it is the structure of the conflict that matters for stock markets, and not the military position or the goals of the US. But even if the driving force behind increasing stock prizes at the onset of a war is the participation of the US, this does not resolve the "war puzzle", but rather raises the new question of how the active role of the US influences the stock market.

Also note that one might argue that the fact that catastrophic outcomes were unlikely for the US during World War II contradicts the fact that Germany proceeded with comprehensive propaganda related to weapons of mass destruction. Their use did eventually not materialize. This seeming contradiction can be resolved by the interpretation of German propaganda as a non-plausible threat to the US. It may also be regarded as a deterrence toward the US (see Schelling (1966)). In particular, propaganda may have been used as a bargaining power to prevent the US from intervening.

\subsection{Ambiguity averse investors}

An alternative explanation that seems to be natural is to assume that investors show ambiguity aversion. At first the ambiguity about the probability of a war breaking out makes people shy away from the stock market and hence leads to lower stock prices. This effect stops as soon as it becomes clear that a war is indeed starting for sure and uncertainty is reduced (Schneider and Troeger (2006)). Guidolin and LaFerrara (2010) suggest that the initiation of conflict can been seen as a sign of resolve and investors tend to show positive reactions by buying stocks. 
However, this seemingly natural behavioral explanation cannot accommodate our empirical data, as ambiguity cannot make an ambiguous situation seem worse than its worst possible outcome. In this situation, that would mean that, even though the probability of the start of a war is uncertain and hence ambiguous, an ambiguity-averse investor would still prefer this situation over a situation where the war has started for sure.

\subsection{Uncertainty about investment decisions}

Another idea to resolve the puzzle is to consider the uncertainty about a war as an uncertainty about the decision between different portfolio allocations: in the case of a peaceful resolution an investor should have invested in different assets than in the case of a war. While it is uncertain which of the two outcomes will occur, it might be optimal for an investor to stay out of the stock market entirely, or at least to reduce their holdings substantially.

To study this idea more in detail, we describe a small model.

When facing the possibility of the outbreak of a war, an investor has to decide between investing in two different portfolios, a "war portfolio" that will be successful if a war breaks out, and a "peace portfolio" that will be successful if the conflict ends in a peaceful resolution. We summarize the four potential outcomes in the following table ${ }^{12}$ :

\begin{tabular}{lcc}
\hline & $\begin{array}{l}\text { war breaks out } \\
\text { (probability } \boldsymbol{p})\end{array}$ & $\begin{array}{l}\text { peaceful resolution } \\
\text { (probability } \mathbf{1}-\boldsymbol{p})\end{array}$ \\
\hline war portfolio & $a$ & $-b$ \\
peace portfolio & $-c$ & 1 \\
\hline
\end{tabular}

Assuming that it is in any case bad for the investor to speculate on the wrong outcome, we have $a, b, c \geq 0$. The expected payoff of the investor now depends on his portfolio decision. If he decides on the war portfolio, it is $a p-b(1-p)$. If he decides instead on the peace portfolio, it is $(1-p)-$ $c p$ (see Figure 7). Obviously, the war portfolio is better for large values of $p$ and worse for small values. As a short computation shows, the cut-off point is at

$$
p^{*}=\frac{1+b}{1+a+b+c} \text {. }
$$

$<$ Figure 7 about here>

This model indeed predicts the observed pattern: an increase in $p$ makes the peace portfolio less and less attractive. Consequently, investors will sell the corresponding stocks. At the same time, however, the war portfolio is still even less attractive, thus the falling prices of the peace portfolio stocks can not be matched by rising prices of stocks in the war portfolio. Once the probability of war reaches $p^{*}$, the pattern changes: now, war stocks become more and more attractive, thus investors buy them and the overall market starts to rise.

In order to find a probability $p^{*}$ that is close to one and thus in line with our empirical evidence, $b$ needs to be sufficiently large, thus the potential loss when choosing a war portfolio, but encountering a peaceful resolution, should be fairly large. 
Theoretically, we can explain the puzzle in this way, but how is it in reality?

How can we test empirically whether this model indeed explains the war puzzle? The general idea is that different stocks should show a different pattern during the different phases before an outbreak of the war: stocks that are in the "peace portfolio", i.e. stocks that would benefit from a peaceful resolution of the conflict, should initially be sold whenever the likelihood of a war increases. Thus we would expect them to follow the generally observed pattern of the stock market, but only before the outbreak of the war: at that point these stocks should not increase significantly, as there is no reason for investors to purchase them once it is clear that the "war portfolio" is the right investment.

Stocks in the "war portfolio" instead should follow the increase of the stock market at the start of the war, but not its previous decrease whenever the war became more likely.

A simple empirical test is now possible by looking at differences between sectors that should clearly be in the war portfolio (weapon-related industry) and sectors that should clearly be in the peace portfolio (e.g., travel-related industry). It turns out, however, that as convincing as the theoretical idea is, it thoroughly fails this simple but clear-cut test: in fact, whereas sectors that one would undoubtedly assign to the peace portfolio (e.g., travel stocks, like airlines) increased most at the outbreak of the war, stocks in the war portfolio (weapon manufacturers) did not.

To sum up, this explanation looks good in theory, but unfortunately does not help to resolve the puzzle in reality.

\subsection{Mean-variance preferences}

Finally there is a rather unexpected possible explanation for the phenomenon: classical meanvariance preferences. Indeed, this concept could explain the observed data surprisingly well. One could argue that people do not buy when it is unsure what is going to happen due to their variance aversion, even though the expected return might still be a little bit better than when the war has finally started. In this sense the observed phenomenon could be related to the mean-variance paradox.

To formalize this idea, we assign average expected returns $\mu_{W}$ and $\mu_{P}$ to the two potential outcomes (war and peace). We denote the probability of a war by $p$, and compute the variance of the twooutcome lottery $\left(\mu_{W}\right.$ with probability $p$ and $\mu_{P}$ with probability $\left.1-p\right)$ as

$$
\operatorname{var}(p)=(1-p) p\left(\mu_{P}-\mu_{W}\right)^{2} .
$$

The variance is zero for $p=0$ (i.e. peace is sure) or $p=1$ (i.e. war is sure) and maximal for $p=1 / 2$ (see Figure 8).

\section{$<$ Figure 8 about here $>$}

Typical indifference curves for a mean-variance investor with utility $\mu-\alpha \sigma^{2}$ are also shown in Figure 8. Looking at the indifference curve through the point $\left(0, \mu_{W}\right)$ (i.e. a certain war) we see that this investor would prefer a certain war $(p=1)$ over a situation where $p$ is large, but still smaller than one. 
When the probability $p$ increases from zero to one, at first the situation worsens for the investor (who consequently would value stocks less), but after a certain point (in our model at $p^{*}=$ $(\propto-1) / \propto$, as a short computation shows) there is indeed a perceived improvement for the investor, explaining the increase in stock prices at the outbreak of a war.

\section{Conclusions}

We have observed that stock market prices react very sensitively to the probability of the outbreak of a major war. The pattern that was shown for several wars during the last century demonstrates that an increase in the likelihood of war decreases stock prices and vice versa. What is puzzling, however, is that once a war breaks out, stock market prices do not decrease further, but do the very opposite and increase significantly. This was true for all wars with a more or less lengthy prologue. Wars that occur "out of the blue" show a different pattern in that their sudden outbreak tends to decrease stock market prices. These results are certainly a challenge for classical asset pricing models.

Mean-variance preferences of investors might be able to explain the observed pattern. There could, however, be different explanations for this puzzle based on other behavioral factors. Future research, e.g. with the help of laboratory experiments, might be able to shed more light on this puzzle.

\section{Acknowledgement}

We thank our students Marco Lang, Laura Leoni, Raphael Müller and Thomas Rast for their help with the data collection and analysis as well as Florian Herzog from swissQuant, Yakov Amihud and Christian Ehm for useful comments. Support by the National Centre of Competence in Research "Financial Valuation and Risk Management" (NCCR FINRISK), Project A1, "Behavioural and Evolutionary Finance", and by the University Priority Program "Finance and Financial Markets" of the University of Zurich is gratefully acknowledged. 


\section{Appendix}

\section{Tables}

\begin{tabular}{lcc}
\hline & Saddam Security June & Iraq war news \\
\hline Saddameter & $\rho=0.86$ & $\rho=0.66$ \\
Saddam Security June & $N=56$ & $N=81$ \\
& & $\rho=0.64$ \\
& & $N=78$ \\
\hline
\end{tabular}

Table 1: Correlations between different proxies for the probability of war. All correlations are significant at the $1 \%$ level and use the largest available number of days from the discussed time series.

\begin{tabular}{llcc}
\hline & & intercept & intercept and trend \\
\hline levels & SP500 & -1.5167 & -2.5662 \\
& news & 0.1771 & $-7.0122^{* * *}$ \\
\multirow{2}{*}{ first differences } & Saddameter & -0.5129 & -1.8901 \\
& SP500 & $-9.6884^{* * *}$ & $-9.6221^{* * *}$ \\
& news & $-7.7683^{* * *}$ & $-7.8207^{* * *}$ \\
& Saddameter & $-7.8386^{* * *}$ & $-7.7840^{* * *}$ \\
\hline
\end{tabular}

Table 2: Iraq War: ADF test statistics for unit roots.

\begin{tabular}{llcc}
\hline & & intercept & intercept and trend \\
\hline levels & $\varepsilon_{t}=S P 500_{t}-\beta_{0}-\beta_{1}$ news & $-3.0972^{* *}$ & $-5.4364^{* * *}$ \\
& $\varepsilon_{t}=S P 500_{t}-\beta_{0}-\beta_{1}$ Saddameter $_{t}$ & $-3.8389^{* * *}$ & $-3.7985^{* *}$ \\
first differences & $\varepsilon_{t}=S P 500_{t}-\beta_{0}-\beta_{1}$ news & $-13.2052^{* * *}$ & $-13.1416^{* * *}$ \\
& $\varepsilon_{t}=S P 500_{t}-\beta_{0}-\beta_{1}$ Saddameter $_{t}$ & $-9.2592^{* * *}$ & $-9.2003^{* * *}$ \\
\hline
\end{tabular}

Table 3: Iraq War cointegration tests: ADF test statistics for unit roots in residuals $\varepsilon_{t}$. 


\begin{tabular}{|c|c|c|c|c|c|}
\hline $\begin{array}{l}\text { war } \\
\text { method } \\
\text { likelihood proxy }\end{array}$ & $\begin{array}{l}\text { Iraq } \\
\text { ECM } \\
\text { news }\end{array}$ & $\begin{array}{c}\text { Iraq } \\
\text { ECM } \\
\text { Saddameter }\end{array}$ & $\begin{array}{c}\text { WWII } \\
\text { first differences } \\
\text { news }\end{array}$ & $\begin{array}{c}\text { Vietnam } \\
\text { first differences } \\
\text { news }\end{array}$ & $\begin{array}{c}\text { Gulf War } \\
\text { first differences } \\
\text { news }\end{array}$ \\
\hline \multirow[t]{2}{*}{$\Delta n e w s_{t-1}$} & & & $-0.1946^{* *}$ & $-0.1160^{* * *}$ & -0.2207 \\
\hline & & & $(0.0741)$ & $(0.0384)$ & (0.1324) \\
\hline \multirow[t]{2}{*}{$\Delta$ news $_{t}$} & $-0.5072 * * *$ & & $-0.2844 * * *$ & -0.0456 & $-0.2885^{* *}$ \\
\hline & $(0.1835)$ & & $(0.0863)$ & (0.0384) & $(0.1281)$ \\
\hline \multirow[t]{2}{*}{$\Delta n e w s_{t+1}$} & & & $-0.2651 * * *$ & & \\
\hline & & & $(0.0697)$ & & \\
\hline \multirow[t]{2}{*}{$n_{e w s_{t-1}}$} & $-3.6611^{* * *}$ & & & & \\
\hline & $(0.5644)$ & & & & \\
\hline \multirow[t]{2}{*}{$\Delta \operatorname{Sadd}_{t-1}$} & & $-1.1147 * *$ & & & \\
\hline & & $(0.4927)$ & & & \\
\hline \multirow[t]{2}{*}{ Sadd $_{t-1}$} & & $-2.3051 * * *$ & & & \\
\hline & & (0.1892) & & & \\
\hline \multirow[t]{2}{*}{$\triangle S P 5_{00}{ }_{t-2}$} & -0.0530 & 0.0512 & & & 0.1588 \\
\hline & (0.1104) & (0.1110) & & & (0.1170) \\
\hline \multirow[t]{2}{*}{$\Delta D J I_{t-2}$} & & & -0.0004 & $0.1519 * * *$ & \\
\hline & & & (0.1181) & $(0.0553)$ & \\
\hline \multirow[t]{2}{*}{$\gamma$} & $-0.2274 * * *$ & $-0.3940 * * *$ & & & \\
\hline & $(0.0681)$ & $(0.1020)$ & & & \\
\hline \multirow[t]{2}{*}{ constant } & & & 0.1827 & 0.2032 & 0.1788 \\
\hline & & & (0.1859) & (0.1609) & $(0.3735)$ \\
\hline$R^{2}$ & 0.1680 & 0.2767 & 0.2276 & 0.0510 & 0.1098 \\
\hline$N$ & 78 & 78 & 69 & 311 & 72 \\
\hline From & Nov 21, 2002 & Nov 21, 2002 & May 25, 1939 & May 6, 1964 & Oct 10,1990 \\
\hline to & March 18, 2003 & March 18, 2003 & Aug 31, 1939 & March 12, 1965 & Jan 1, 1991 \\
\hline
\end{tabular}

Table 4: Regression results for the effect of the war likelihood on stock prices. Standard errors are given in parenthesis. ${ }^{*}$ denotes significance at $10 \%, * *$ at $5 \%$, and $* * *$ at $1 \%$ level.

\begin{tabular}{lcc}
\hline & costs in billion 2008 US\$ & \% of GDP \\
\hline World War II & 4114 & 35.8 \\
Korean War & 320 & 4.2 \\
Vietnam War & 686 & 2.3 \\
Gulf War & 96 & 0.3 \\
Iraq War & 648 & 1.0 \\
Afghanistan War & 171 & 0.3 \\
\hline
\end{tabular}

Table 5: List of the most costly wars to the US (source: Stephen Daggett, CRS Report for Congress, costs of major U.S. wars, July 2008).

\begin{tabular}{lccccc}
\hline & critical event & \multicolumn{4}{c}{ estimated breaks } \\
\hline & & S\&P 500, DJI & Nikkei & DAX & Eurostoxx \\
Iraq War & Mar 20, 2003 & Mar 18, 2003 & Mar 7, 2003 & Apr 7, 2003 & Feb 25, 2003 \\
\hline
\end{tabular}




\begin{tabular}{lllll}
\hline Gulf War & Jan 29, 1991 & Feb 4, 1991 & Feb 5, 1991 & Jan 30, 1991
\end{tabular}

Table 6: Analyses for structural breaks in other large stock market indices.

\begin{tabular}{lccc}
\hline & \multicolumn{3}{c}{ stock market reaction to: } \\
\hline & increasing prob. & expected start & surprising start \\
WWII (start in Europe) & $0 \%-99 \%$ & $99 \%-100 \%$ & $0 \%-100 \%$ \\
WWII (Pearl Harbor) & $\searrow$ & $\nearrow$ & $\searrow$ \\
Korean War & & & $\searrow$ \\
Vietnam War & $\searrow$ & $\nearrow$ & $\searrow$ \\
Gulf War (Kuwait invasion) & & $\nearrow$ & \\
Gulf War ("desert storm") & $\searrow$ & $\nearrow$ & \\
Afghanistan War & $*$ & $\lambda$ & \\
Iraq War (2003) & $\searrow$ & & \\
\hline
\end{tabular}

Table 7: Summary of stock markets' reactions to news. ${ }^{*}$ indicates a lack of data in order to investigate this point. 


\section{Figures}
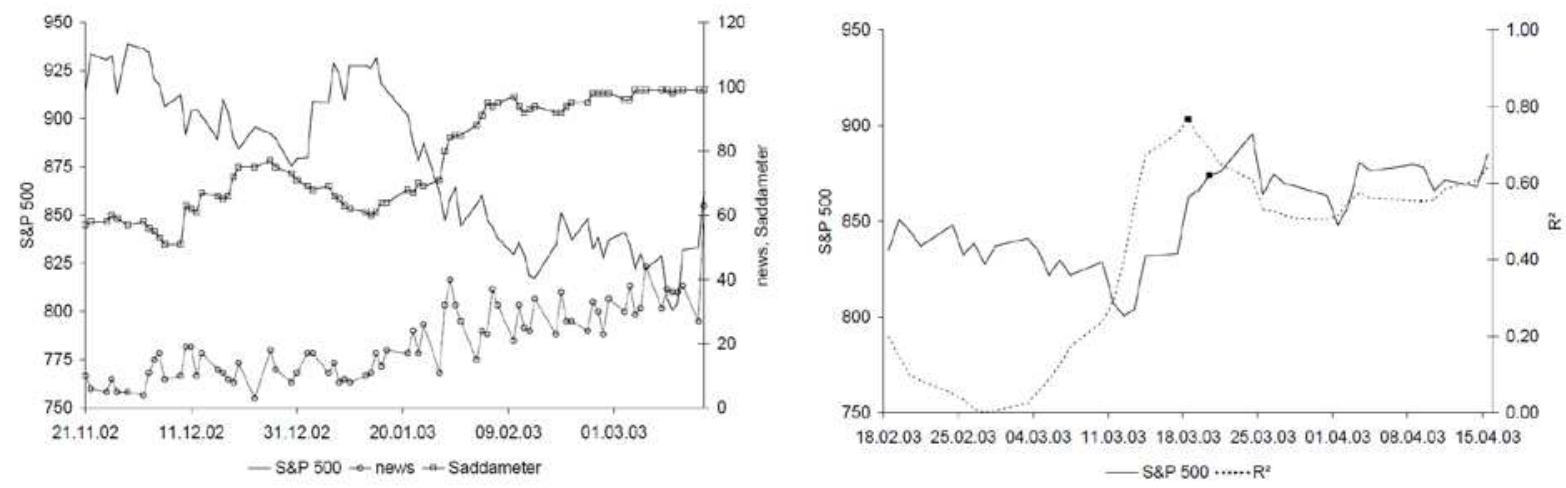

Figure 1a and 1b: Probability of a war./Structural break analysis. Development of the S\&P 500 at the beginning of the Iraq War. The largest local $R^{2}$ was reached for $\tilde{t}=$ March 18, 2003 while the invasion of Iraq took place two days later on March 20, 2003.
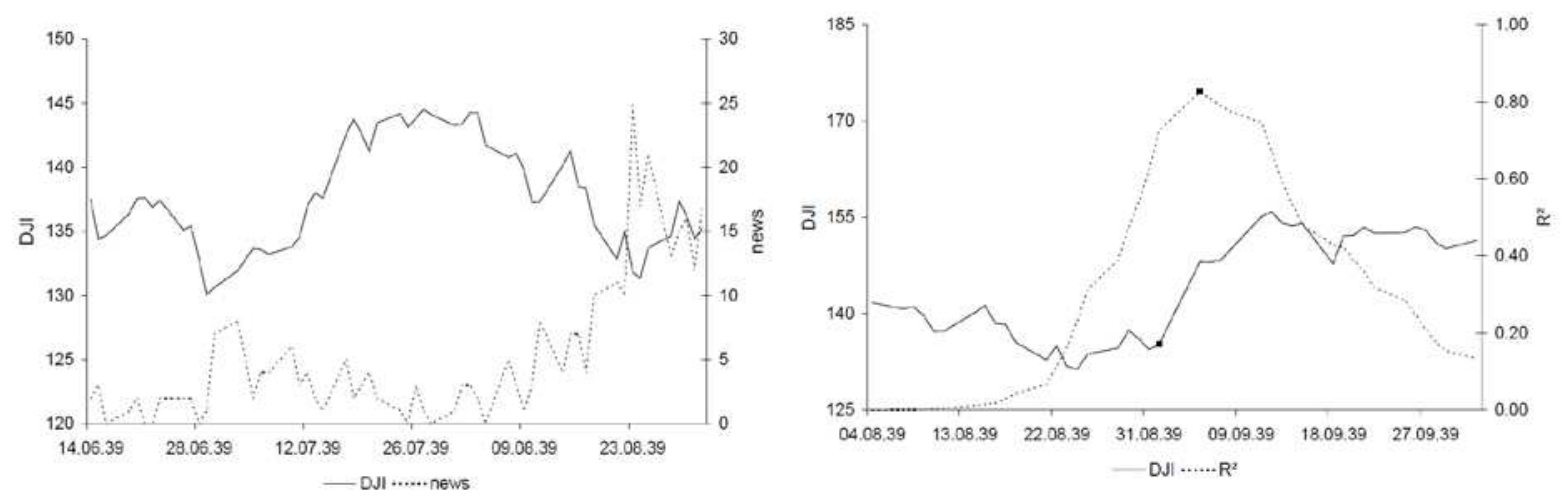

Figure 2a and 2b: Probability of a war./Structural break analysis. Development of the Dow Jones Index at the beginning of World War II. The largest local $R^{2}$ was reached for $\tilde{t}=$ September 5, 1939 while the German attack of Poland took place on September 1, 1939. 

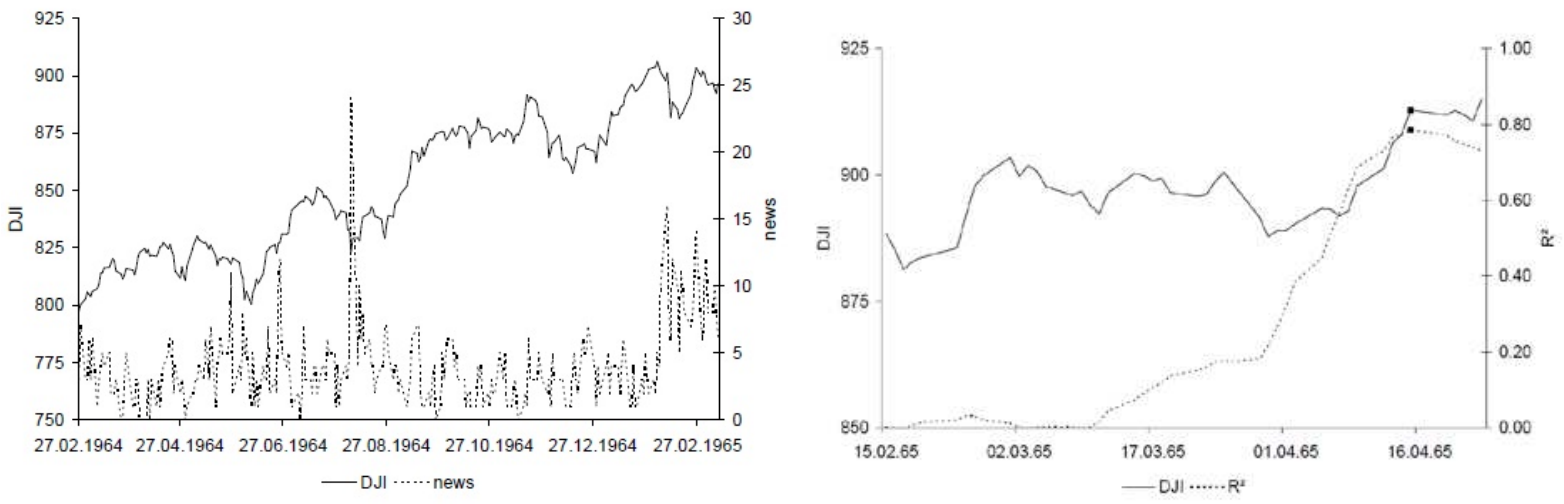

Figure 3a and 3b: Probability of a war./Structural break analysis. Development of the Dow Jones Index during the Vietnam War. The largest local $R^{2}$ was reached for $\tilde{t}=$ April 15, 1965 which coincides with the first US and South Vietnamese bombing of Viet Cong positions on that day.

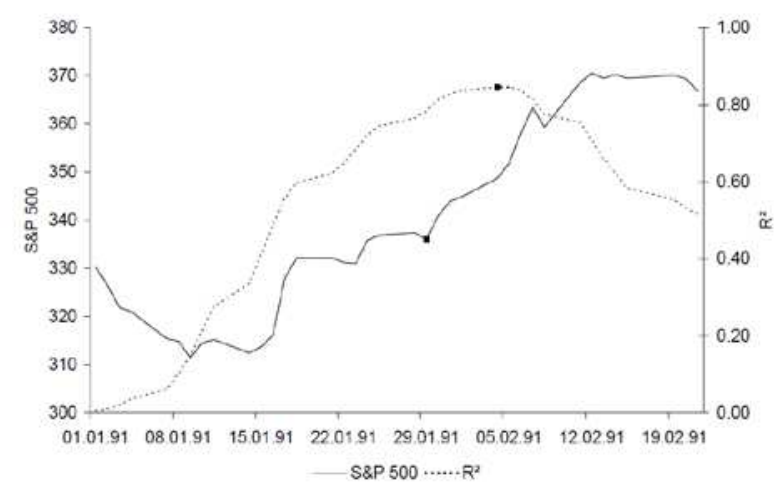

Figure 4: Development of the S\&P 500 and explanatory power of structural break analysis at the beginning of the Gulf War. The largest local $R^{2}$ was reached $\tilde{t}=$ February 4, 1991 while the Battle of Khafji took place on January 29, 1991. 

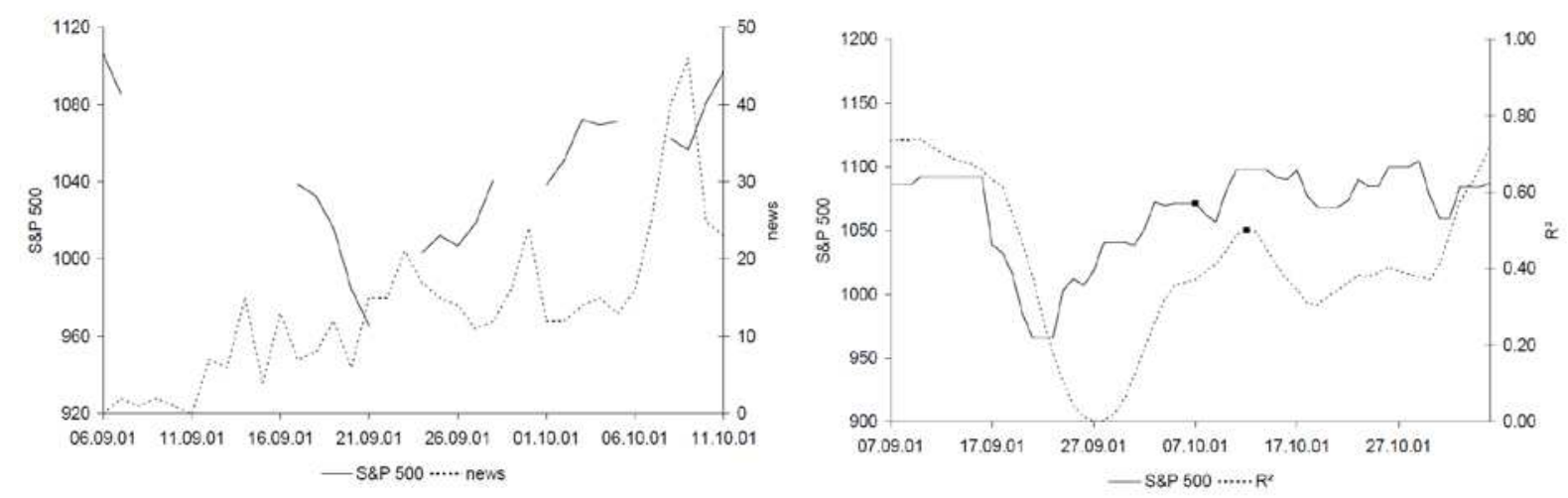

Figure 5a and 5b: Probability of a war./Structural break analysis. Development of the S\&P 500 during the Afghanistan War. The largest local $R^{2}$ was reached for $\tilde{t}=$ October 12, 2001 while the air attack took place on October 7, 2001.
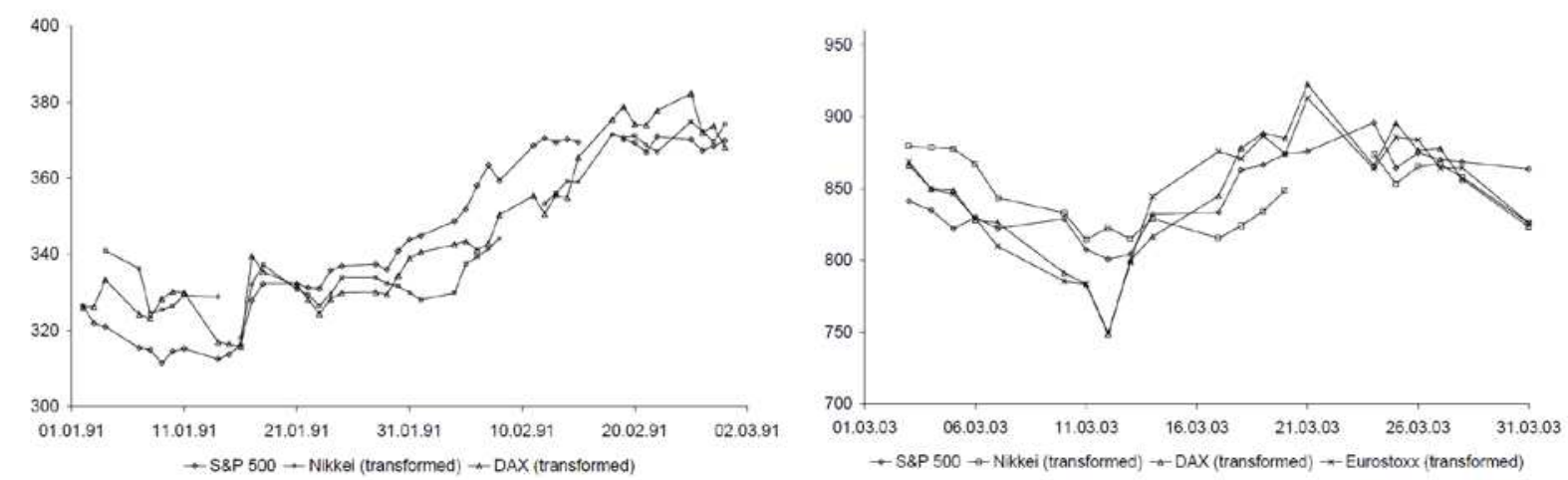

Figure 6a and 6b: Gulf War./Iraq War. Comovement of other stock market indices. For the sake of comparability, the data series of Nikkei, DAX, and Eurostoxx are linearly transformed such that all series have a mean equal to the mean of the S\&P 500. 


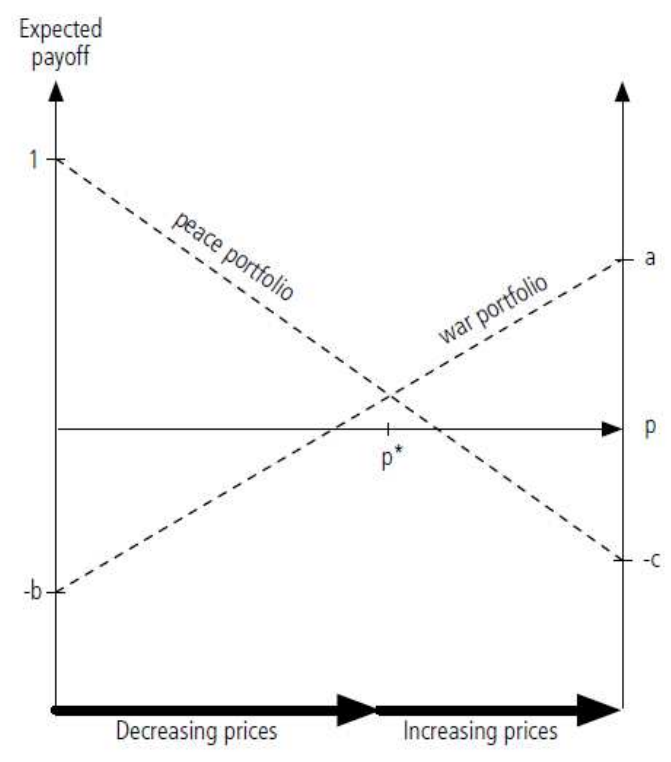

Figure 7: Investors switching from a "peace portfolio" to a "war portfolio" when the probability of war increases beyond a threshold $p^{*}$ could explain the war puzzle.

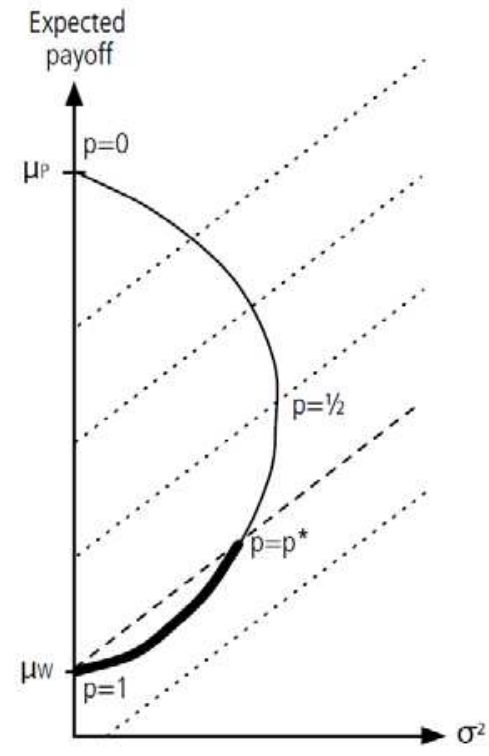

Figure 8: Mean-variance preferences can explain the war puzzle. Here, $\mu_{P}$ and $\mu_{W}$ are the returns in case of peace and war, respectively. $\sigma$ is the variance of the situation, depending on the probability of war. It is maximal when the probability is $1 / 2$ (maximal degree of uncertainty). The dashed lines are indifference curves, i.e. they mark combinations of mean and variance on which an investor would be indifferent. A certain war is preferred over an uncertain situation with a high probability of war (points on the thick line). 


\section{References}

Amihud, Y., and A. Wohl (2004): "Political News and Stock Prices: The Case of Saddam Hussein Contracts," Journal of Banking \& Finance, 28(5), 1185-1200.

Chappell, D., and R. Eldridge (2000): "Evidence of Market Inefficiency in a War Environment," Applied Financial Economics, 10(5), 489-492.

Collier, P., and A. Hoeffler (1998): "On Economic Causes of Civil War," Oxford Economic Papers, 50(4), 563-573.

Cutler, D., J. Poterba, and L. Summers (1998): “What Moves Stock Prices?," Journal of Portfolio Management, 15(3), 4-11.

Elmendorf, D., M. Hirschfeld, and D. Weil (1996): "The Effect of News on Bond Prices: Evidence from the United Kingdom, 1900-1920," Review of Economics and Statistics, 78(2), 341-344.

Frey, B., and M. Kucher (2000): "History as Reflected in Capital Markets: The Case of World War II," Journal of Economic History, 60(2), 468-496.

Goldstein, J. (1992): “A Conflict-Cooperation Scale for WEIS Events Data," Journal of Conflict Resolution, 36(2), 369-385.

Guidolin, M., and E. La Ferrara (2010): "The Economic Effects of Violent Conflict: Evidence from Asset Market Reactions," Journal of Peace Research, 47(6), 671-684.

Holsti, O., and R. North (1966): "Comparative Data from Content Analysis: Perceptions of Hostility and Economic Variables in the 1914 Crisis in Comparing Nations," in The Use of Quantitative Data in Cross-National Research, ed. by R. Merritt, and S. Rokkan, pp. 169-199. Yale University Press, New Haven.

Keynes, J. (1919): The Economic Consequences of the Peace. Macmillan, London, reprint edn. 1971.

Li, Q., and D. Sacko (2002): "The (Ir)relevance of Militarized Interstate Disputes for International Trade," International Studies Quarterly, 46(1), 11-43.

Niederhoffer, V. (1971): "The Analysis of World Events and Stock Prices," Journal of Business, 44(2), 193-219.

Powell, R. (2002): "Bargaining Theory and International Conflict," Annual Review of Political Science, 5(1), 1-30.

Rigobon, R., and B. Sack (2005): "The Effects of War Risk on US Financial Markets," Journal of Banking \& Finance, 29(7), 1769-1789.

Russett, B., and E. Hanson (1975): Interest and Ideology: The Foreign Policy Beliefs of American Businessmen. Freeman, San Francisco.

Schelling, T. (1966): Arms and Influence. Yale University Press, New Haven. 
Schneider, G., and V. Troeger (2006): "War and the World Economy: Stock Market Reactions to International Conflicts," Journal of Conflict Resolution, 50(5), 623-645.

Wolfers, J., and E. Zitzewitz (2009): "Using Markets to Inform Policy: The Case of the Iraq War," Economica, 76(302), 225-250.

\footnotetext{
${ }^{1}$ Standard predictive models are often constructed such that changes in variables at time $t+1$ are explained by changes in variables at time $t$. In our case this approach would require to use a variable for the war likelihood which realizes prior to actual changes in the stock market. However, since our argument is to use the news proxy as a flexible probability measurement which is available for different wars over time, the functional forms used here slightly differ from standard models due to the delay of news publication. This however does not alter the models' predictive power.

${ }^{2}$ Also, the error correction parameter $\gamma$ is significantly negative as expected for both types of probability measurements.

${ }^{3}$ That is, the data set ranges from $\tilde{t}-25$ to $\tilde{t}+25$ days around $\tilde{t}$.

${ }^{4}$ We use this type of structural break analysis since we are interested in whether there exists an instantaneous jump in the stock market index at the onset of a war. An alternative question would be whether there are possible changes in the trend of the stock market. For that purpose a model testing for changes in expected growth rates of stock returns may be appropriate (see Amihud and Wohl (2004)).

${ }^{5}$ Note that the estimated structural break on March 18 coincides with the beginning of the US ultimatum to Saddam Hussein. Investors might have anticipated that this ultimatum would not be agreed upon which caused an early rise in stock market values.

${ }^{6}$ CRS Report for Congress, costs of major US wars, July 2008.

${ }^{7}$ The Gulf War is often also referred to as Second Gulf War or Persian Gulf War.

${ }^{8}$ Although it would be interesting to see how stock markets evolved in the countries were war actually took place, this analysis is often not feasible. Either stock exchanges were not yet institutionalized, or controlled by the government so that data would not be reliable, or data is not available.

${ }^{9}$ Due to issues of data availability, we could not perform a similar analysis for global wars having occurred earlier in history.

${ }^{10} \mathrm{Li}$ and Sacko (2002) find that an unexpected onset of a military dispute reduces bilateral trades more severely.

${ }^{11}$ This holds true unless we studied intra-day data which in most of these cases is not available.

${ }^{12}$ For simplicity, we normalize the investor's return for a "peace portfolio" to one in the case of a peaceful resolution.
} 